\title{
MODERNISASI DAN TERBENTUKNYA GAYA HIDUP ELIT EROPA DI BRAGAWEG (1894-1949)
}

\section{MODERNIZATION AND THE LIFESTYLE OF THE EUROPEAN ELITE IN BRAGAWEG (1894-1949)}

\author{
Hary Ganjar Budiman \\ Balai Pelestarian Nilai Budaya Jawa Barat \\ Jl. Cinambo No. 136, Ujungberung, Bandung \\ e-mail: hgbudiman@gmail.com
}

\begin{abstract}
Abstrak
Penelitian ini menguraikan perubahan Bragaweg dari 1894 hingga 1949. Selain itu, penelitian ini menguraikan bentuk aktivitas golongan Eropa di Jalan Braga yang merepresentasikan nuansa modern di masa kolonial. Metode sejarah digunakan untuk mengkontruksi kisah Braga. Untuk menunjang analisis, penelitian ini, penulis memakai konsep modernisasi yang digunakan Lawrence V. Stockman. Menurutnya, modernisasi tidak menciptakan sesuatu yang baru tetapi menerima sesuatu yang baru dari bangsa atau Negara lain yang lebih maju. Pada awalnya elit Eropa berusaha beradaptasi, kemudian mengupayakan terbentuknya kehidupan khas Eropa di negeri jajahan. Bragaweg adalah gambaran suksesnya upaya elit Eropa tersebut. Transformasi Bragaweg merepresentasikan pertumbuhan ekonomi di kawasan tersebut; dari munculnya toko kebutuhan pokok hingga munculnya toko barang mewah dan industri. Kesan modern terlihat dari gaya hidup yang dipraktikkan elit Eropa serta lengkapnya sarana dan teknologi di kawasan Bragaweg. Pada masa perang kemerdekaan, suasana gemerlap Eropa redup dan digantikan dengan suasan perang.
\end{abstract}

Keywords: Bragaweg, modern, gaya hidup, elit Eropa.

\section{Abstract}

This study describes the Bragaweg changes from 1894 to 1949. In addition, this study describes the form of European-style activity in Braga Street that represents the modern nuances of the colonial period. The historical method is used to construct the Braga story. To support the analysis of this study, the author uses the concept of modernization of Lawrence V. Stockman. He stated that modernization does not create something new but accept something new from another nation or other developed country. At first the European elite tried to adapt, then seek the formation of a typical European life in the colony. Bragaweg is a picture of the success of the European elit. The Bragaweg transformation represents economic growth in the region; From the emergence of staple stores to the rise of luxury and industrial goods stores. Modern impression is seen from the lifestyle practiced by the European elite and the full range of facilities and technology in the Bragaweg region. In the war of independence, the sparkling atmosphere of Europe was dimmed and replaced by the atmosphere of war.

Keywords: Bragaweg, modern, life style, European elite.

\section{A. PENDAHULUAN}

Kota-kota di Hindia Belanda tumbuh dengan cepat sepanjang 1900 hingga 1925. Pertambahan penduduk mengalami lonjakan yang tinggi. Misalnya
Batavia mengalami lonjakan jumlah penduduk hingga $130 \%$, Surabaya $80 \%$, Semarang $100 \%$, dan Bandung $325 \%$. Pada awal abad ke-20, muncul istilah revolutiebouw yang bisa dimaknai sebagai 
revolusi dalam pembangunan (Mrazek, 2006). Didukung oleh perkembangan teknologi dan kebijakan liberalisasi ekonomi pada penghujung abad ke-19, orang-orang Eropa, termasuk para pengusaha dan keluarga pegawai pemerintah kolonial, semakin banyak datang ke Hindia Belanda. Mereka beradaptasi dengan kondisi tropis di Hindia Belanda, menciptakan lingkungan ideal berdasarkan persepsi ${ }^{1}$ golongan Eropa. Lingkungan ideal menurut persepsi Eropa ini, di antaranya diwujudkan dalam bentuk jalan beraspal, lampu penerangan jalan, taman kota, lahan pemakaman, perluasan lahan kota dan pembangunan gedung perkantoran berkonsep Nieuw Indische Bouwstijl (Kunto, 1986, 2014). Menjelang abad ke-20, kota-kota di Jawa-sebut saja misalnya Batavia, Bandung, Malang, dan Semarangsemakin berkembang pembangunannya serta dinamis kehidupan masyarakatnya (Colombijn dkk., 2005)

Seperti halnya Batavia, Malang, dan Semarang, Bandung merupakan salah satu dari sedikit kota yang merasakan modernisasi paling mula di Hindia Belanda $^{2}$, salah satu hasil pembangunan

\footnotetext{
${ }^{1}$ Munculnya julukan seperti Venetie van Java (untuk Batavia), Holland Tropische Stad (Malang), Costa Brava van Java (Semarang), Switzerland van Java (Garut) merupakan indikasi betapa kota di Hindia Belanda dibentuk berdasarkan persepsi ideal tentang kota di Eropa.

2 Selama Periode 1810 - 1906 Bandung mengalami perubahan sosial. Perubahan itu bergerak secara unilinear, dari kehidupan tradisional kemudian berkembang ke arah kehidupan modern. Proses perubahan mencapai puncak dengan pembentukan Gemeente Bandung pada 1 April 1906. Teknologi kereta di Bandung terbukti mempercepat kehidupan kota (Hardjasaputra, 2002). Bandung merupakan kota pertama di Hindia Belanda yang memiliki biro arsitek swasta, yaitu Technisch Bureau Biezeld \& Mooje ${ }^{2}$. Bandung pula yang sempat direncanakan menjadi Ibukota Hindia Belanda (Dienaputra, 2015).
}

Kota Bandung bisa dilihat di Jalan Braga. Jalan Braga sering disebut mewakili citra Parijs van Java yang tersemat di Kota Bandung. Dienaputra (2015: 817) menyatakan bahwa sentra dari sebagian besar denyut kehidupan gaya Eropa di Bandung pada dasarnya berada di sekitar jalan Braga.

Seperti dijelaskan oleh Haryoto Kunto (1984, 2014), di Braga terdapat segala jenis pertokoan, restoran, tempat hiburan, gedung pertemuan orang-orang Eropa, bioskop hingga tempat pelacuran pun ada di sana. Pada jalan Braga pula, uang berputar dan perekonomian melaju. Pada masa itu lahir ungkapan dari para pengusaha perkebunan Eropa, "naar beneden geld halen!" yang "artinya ke bawah mengambil uang". Maksud ungkapan tersebut tentu saja dari tempat tinggal para penguasaha Eropa di daratan tinggi Bandung, menuju ke Braga guna mengambil uang di bank. Pada awal abad ke-20, di Jalan Braga terdapat 3 unit bank: Escompto, DENIS, dan Javasche Bank. Sepanjang 1925 hingga 1930, uang nasabah yang tersimpan di DENIS Bank mengalami peningkatan hingga $900 \%$, dari 504.500 gulden meningkat hingga 4.718.500 gulden ${ }^{3}$.

Berdasarkan uraikan di atas, meneropong Jalan Braga yang dijuluki sebagai dee meest Europeesche winkelstraat van indie (Pusat perbelanjaan nomor satu Bangsa Eropa di Hindia Belanda) menjadi menarik untuk dikaji. Sebagai sebuah jalan yang tak lebih dari 1 $\mathrm{km}$ itu, sebagai sebuah lokus kecil di tengah kota Bandung, agaknya menjadi penting untuk menelisik bagaimana mungkin Jalan Braga bisa dijuluki dee meest Europeesche winkelstraat van indie? Kenapa harus Jalan Braga, bukan Jalan

\footnotetext{
3. Economic-booming terjadi di Bandung pada 1920-an akibat tingginya permintaan hasil perkebunan di wilayah Priangan. Hal ini sejalan dengan pertambahan penduduk Eropa, dan percepatan pembangunan kota (Kunto, 1986; Hardjasaputra, 2002).
} 
Riau atau Jalan Dago misalnya. Pada titik ini menelusuri transformasi jalan Braga menjadi perlu. Banyaknya pertokoan di Braga pada masa kolonial sebagaimana digambarkan oleh Hutagalung dan Nugraha (2006) bisa menjadi parameter untuk membuktikan bagaimana aktivitas masyarakat di Braga bisa merepresentasikan kesan modern ${ }^{4}$ di kota kolonial, bagaimana pula gaya hidup Eropa bisa terbentuk dan dipraktikkan.

Berdasarkan uraian di atas, penelitian ini mecoba mengerucutkan rumusan masalah menjadi tiga. (1) Bagaimana perubahan Jalan Braga dari sebuah jalan biasa menjadi sebuah jalan modern yang identik dengan kehidupan orang-orang Eropa; (2) Ciri apa saja yang menunjukkan bahwa Braga adalah kawasan modern di masa Hindia Belanda; serta (3) bagaimana pula gaya hidup Eropa yang tumbuh di kawasan tersebut. Melalui rumusan masalah tersebut, penulis mencoba melihat Braga dari dua perspektif. Pertama, dari perkembangan lanskap; dari jalan lengang menjadi jalan yang penuh dengan toko dan menjadi pusat aktivitas. Kedua, melihat Braga sebagai ruang yang diisi oleh aktivitas manusianya, di mana praktik kebudayaan berlangsung.

Kajian ini diharapkan mampu merekonstruksi perubahan yang terjadi di kawasan Braga di tengah kompleksitas perkotaan masa kolonial. Kajian ini juga diharapkan bisa menjadi studi pendahuluan, bila transformasi di Braga ini akan dikaji dalam periodiasi yang lebih panjang. Tahun 1894 adalah titik mula yang penulis ambil dalam penelitian ini. Tahun tersebut menjadi pijakan karena pada tahun tersebut, untuk pertama kalinya sebuah toko milik orang Eropa berdiri di

${ }^{4}$ Rudolf Mrazek (2006) memberi perspektif menarik tentang zaman modern di Hindia Belanda. Selain pesatnya teknologi (kereta, mesin jahit, telepon, dsb.), zaman modern di Hindia Belanda bisa tergambar melaui usahausaha untuk menciptakan higienitas, keteraturan, tata krama, dan perubahan mode busana yang mencolok.
Bragaweg. Tentu pijakan tahun 1894 tidak berlaku ketat, karena indikasi perkembangan Braga sebagai sebuah pusat aktivitas orang Eropa sebetulnya sudah nampak, setidaknya terhitung dari mulai berdirinya Societeit Concordia pada 1879. Jauh sebelum itu, dalam ruang lingkup yang lebih umum, sebetulnya modernisasi di Bandung sudah dirintis sejak Bandung ditetapkan sebagai Ibukota Keresidenan Priangan pada 1864. Titik tuju penelitian ini dibatasi hingga tahun 1949, yaitu terhitung sejak masa revolusi fisik, menjelang pengakuan kedaulatan Indonesia oleh Belanda. Tahun 1949 menjadi batasan karena pada masa tersebut kondisi Jalan Braga tidak kondusif dan mulai ditinggalkan orang-orang Eropa disebabkan situasi perang yang melanda Hindia Belanda.

Memang telah banyak penulis yang membahas Jalan Braga, seperti Haryoto Kunto (1984; 1986), Ridwan Hutagalung dan Taufanny Nugraha (2008), Iwan Hermawan (2010), dan disinggung dalam disertasi Sobana Hardjasaputra (2002). Meski demikian, sejauh penelusuran penulis belum ada penelitian yang meninjau Jalan Braga dengan utuh dari masa ke masa. Penulis tidak menampik bahwa dari sekian karya yang telah ada, banyak data yang bisa dikumpulkan dan direkontruksi dengan sudut pandang yang berbeda. Untuk itu, penelitian ini mencoba memberi sudut pandang baru dengan melihat Braga sebagai representasi modern di kota kolonial. Di sisi lain penulis mencoba melihat Braga sebagai ruang yang bertransformasi berdasarkan aktivitas masyarakat yang mengisinya. Dalam konteks penelitian sejarah, penulis mencoba mengisi celah dengan uraian periodisasi yang lebih panjang dan dengan menambah sumber primer lainya (koran, iklan, dan foto).

Untuk memudahkan analisis, penulis mencoba menggunakan konsep modernisasi yang dikemukakan oleh Lawrence V. Stockman. Ia 
mengungkapkan bahwa modernisasi adalah proses belajar menerima normanorma atau standar-standar yang sudah ada sebelumnya. Modernisasi adalah suatu bentuk resosialisasi, individual maupun kolektif. Dalam pemahaman Stockman, modernisasi ini tidak menciptakan sesuatu yang baru tetapi menerima sesuatu yang baru dari orang lain. Orang lain dalam konteks ini, sering dikaitkan dengan negara yang lebih maju di Barat. Argumen Stockman ini sejalan dengan pendapat Roger dan Havens yang mendefinisikan modernisasi dalam kerangka-kerangka perubahan inovatif dan proses menerima inovasi-inovasi (Daryanto, 1989).

Dikaitkan dengan modernisasi di Braga, khususnya untuk mengerucutkan analisis, penulis juga mencoba menggunakan paradigma yang digunakan Hazel Hahn dalam karyanya Scene of Parisian Modernity, di mana kesan modern di Paris dibaca melalui produk budaya konsumsi yang meliputi media cetak, penerbitan, teknik ritel, pariwisata, promosi kota, fashion, iklan, dan pertunjukan. Pada penelitiannya Hahn meneropong kehidupan perkotaan modern di Paris dengan mengamati sebuah jalan yang menjadi ikon kota yaitu Grand Boulevard, Paris. Mencontoh pada penelitian yang dilakukan Hahn, maka analisis penulis lebih berfokus pada iklan, pertokoan, panggung kemewahan yang dipertunjukkan oleh orang-orang Eropa, teknologi, serta gaya hidup yang dipraktikkan di sepanjang Braga.

\section{A. METODE PENELITIAN}

Tulisan ini menggunakan metode sejarah yang meliputi empat tahapan kerja. (1) tahap heuristik, yaitu pengumpulan sumber. Pada tahap ini, penulis melakukan penelusuran sumber primer tambahan agar mampu menghadirkan kebaruan data. Tambahan sumber primer difokuskan pada terbitan koran abad ke-19 dan pada awal abad ke-20, seperti De Preanger-bode, Bataviaasch Nieuwsblad, dan Java-bode. Penulis juga menggunakan foto sebagai sumber primer, di antaranya foto-foto Bandung awal abad ke-20. Sebagai data penunjang, penulis juga menggunakan sumber video yang menggambarkan Braga sekitar 1910-1930. (2) tahap kritik yaitu mengkaji otentisitas sumber dan kredibilitas sumber. (3) tahap interpretasi, yaitu menafsirkan fakta-fakta serta menetapkan makna dari serangkaian fakta yang diperoleh. (5) tahap historiografi yaitu rekonstruksi yang imajinatif dari masa lampau berdasarkan data yang diperolah dengan menempuh proses menguji dan menganalisis secara kritis rekaman dan peninggalan masa lampau (Herlina, 2011:15).

\section{B. METODE PENELITIAN \\ 1. Awal Mula Keberadaan Bragaweg}

Beberapa litelatur menjelaskan keterangan yang sama bahwa Jalan Braga pada mulanya dikenal sebagai Jalan Pedati atau dalam bahasa Belanda dikenal sebagai Karrenweg (Hardjasaputra, 2002; Kunto, 1986, 1984). Lokasi Jalan Pedati tidak jauh dari alun-alun Bandung, jalan ini pula terhubung dengan Jalan Raya Pos yang dibangun Daendels pada pertengahan 1808. Menurut Sudarsono Katam (2017: 1), pada awal 1800 Jalan Pedati merupakan bagian dari jalan setapak yang menyusuri tepi aliran sungai sampai ke hulu Sungai Cikapundung.

Awal dibukanya Jalan Pedati belum bisa diketahui, namun jalan ini penting untuk menghubungkan akses distribusi kopi dari Jalan Raya Pos dengan gudang kopi milik Andres de Wilde (sekarang Balai Kota) yang sudah dibangun sejak 1819. Penamaan Jalan Pedati pun terkait dengan alat transportasi yang digunakan untuk mengangkut kopi ke gudang milik Andres de Wilde (Sunarwiboro, 2010 dalam Hermawan, 2010). Suasana Bandung ketika itu masih seperti desa, ujung Jalan Pedati rimbun dipenuhi oleh pohon karet dan beringin. Pada malam hari suasannya gelap dan menyeramkan (Kunto, 1986: 329). 
Pada 1835, untuk kelancaran pengangkutan kopi, Bupati R.A. Wiranatakusumah III melakukan perbaikan Jalan Pedati, termasuk perpanjangan akses jalan ke beberapa distrik di luar kota. Pada 1857, sejumlah warung mulai berdiri di pinggir Jalan Pedati. Laju kehidupan di sekitar Jalan Pedati mulai terasa sejak Bandung ditetapkan menjadi pusat Keresidanan Priangan pada 1864, dan didorong pula oleh ditetapkannya Undang-Undang Agraria pada 1870, sehingga pengusaha Belanda/Eropa mulai berdatangan ke Bandung. Tahun 1874 di Jalan Pedati mulai berdiri rumah tembok milik pejabat dan pensiunan Belanda. Terdapat pula beberapa warung dengan bangunan sederhana dan beberapa toko (Hardjasaputra, 2002: 137). Meski demikian, tahun 1876 seorang penginjil Zending menggambarkan Bandung masih serupa desa yang maju (Kunto, 2014: 285).

Latar belakang mulai ramainya Jalan Pedati tidak lepas dari aktivitas para pengusaha perkebunan Eropa (preangerplanters). Mereka biasa berkumpul di sebuah penginapan bernama Thiem. Tingginya intensitas pertemuan dan semakin banyaknya preangerplanters yang bergabung, membuat tempat berkumpul pun berpindah ke sebuah rumah sederhana di Jalan Pedati. Pada 1879, para preangerplanters menguatkan kebiasaan berkumpul dan bersosialisasi mereka dalam bentuk organisasi resmi berbadan hukum dengan nama Societeit Concordia

\footnotetext{
${ }^{5}$ Penentuan letak Societet boleh jadi untuk memudahkan para preangerplanter mendapatkan suplai segala keperluan. Manakala jalur kereta belum dibangun di Bandung, maka sangat masuk akal jika Jalan Raya Pos menjadi rute termudah untuk mengirimkan segala komoditas. Berkumpulnya para preangerplanter dan para elit kota di sekitar Jalan Pedati dan Jalan Raya Pos bisa pula berkait dengan kepentingan bisnis; misalnya pendistribusian hasil komoditas perkebunan ke pelosok Jawa melalui Jalan Raya Pos.
}

(Hutagalung dan Nugraha, 2008; Kunto 2014).

Terbentuknya Societeit Concordia di Bandung menjadi penting dalam memicu terbentuknya pola kehidupan ala Eropa di Jalan Pedati. Setelah Societeit Concordia terbentuk, secara perlahan bertambah pula bangunan yang berdiri di sekitarnya. Pada 1881, jumlah rumah tembok di kawasan Jalan Pedati bertambah menjadi delapan buah. Meski demikian, suasana kota Bandung pada awal tahun 1880-an masih seperti desa. Jalan Pedati masih jelek, belum diperkeras dengan batu. Belum ada lampu penerang jalan, hanya mengandalkan cahaya lampu petromak dari sebuah warung (Hardjasaputra, 2002: 153).

Pada 1882 hiburan baru muncul dengan adanya Toneelvereeniging Braga yang didirikan oleh Pieter Sijhoff. Pertunjukan Tonil (sandiwara) pun ditampilkan sebagai hiburan bagi para elit di Societeit. Aktivitas Tonil di gedung Societeit tak tertampung sehingga pertunjukan Tonil berpindah ke gedung sewaan di ujung selatan persimpangan antara Jalan Pedati dan Jalan Raya Pos. Semenjak ketenaran Toneelvereeniging Braga melejit, lama kelamaan Jalan Pedati pun dikenal sebagai Bragaweg (Jalan Braga) (Kunto, 2014: 284).

\section{Awal Modernisasi di Bragaweg}

Tahun 1884, jalur kereta api dari Cianjur ke Bandung mulai dibuka. Lokasi stasiun kereta baru ini jaraknya tidak

Argumen ini agaknya sejalan dengan pendapat Louis Couprerus dalam novel De Stille Kracht yang mengungkapkan bahwa keberadaan Societet berhubungan dengan proses globalisasi yang didorong oleh perdagangan komoditas perkebunan di awal abad ke-19 (isyharyanto.wordpress.com, diakses 17 Januari 2016). Pertemuan di antara preangerplanters dengan elit kota ini menciptakan ruang publik, di mana orangorang saling bertemu, segala informasi dan kabar berita dipertukarkan. 
begitu jauh dari Bragaweg dan Jalan Raya Pos. Hal ini menyebabkan kehidupan ala Eropa semakin mewarnai di sekitar Jalan Raya $\operatorname{Pos}^{6}$ dan Bragaweg, karena secara alamiah membuat intensitas kedatangan orang-orang Eropa semakin tinggi (Hermawan, 2010). Kondisi ini tentu menciptakan peluang usaha yang potensial bagi para pebisnis. Memasuki tahun 1889, didirikan sebuah hotel megah di Bandung, yaitu Hotel Savoy Homann. Posisi hotel ini berada di pinggir Jalan Raya Pos, tidak jauh dari ujung selatan Bragaweg. Tahun 1890 seorang pebisnis bernama C.A. Hellermann membeli beberapa petak tanah di pinggir Bragaweg. Tanah yang ia beli kemudian dibangun menjadi sebuah toko pada 1894. Toko tersebut menjadi salah satu toko paling mula di Bragaweg, dikenal dengan nama N.V. Hellermann sebagai toko penjual senjata beserta amunisinya (Hutagalung dan Nugraha, 2008; De Preanger Bode, 22 September 1902; De Preanger Bode, 8 Maret 1930). Berdirinya N.V. Hellerman menandai awal modernisasi yang terjadi di Bragaweg karena sejak saat itu mulai berdiri tokotoko dengan ciri Eropa di Braga, yaitu toko yang memang menjual barang-barang khusus untuk kebutuhan orang-orang Eropa.

Pada 1895, Societiet Concordia sebagai perkumpulan elit Eropa mencapai puncak popularitasnya ditandai dengan diresmikannya gedung baru yang lebih megah untuk berkumpul. Empat tahun setelah berdirinya N.V. Hellerman (1898), di sebelah utara Bragaweg berdiri toko "Provisien en Dranken" ("P en D") yang didirikan oleh C.M. Luyks (Hutagalung

\footnotetext{
${ }^{6}$ Menurut Haryoto Kunto, setelah jalur kereta api dibuka pada 1884 di Bandung, geliat ekonomi muncul di sepanjang Jalan Raya Pos, ditandai dengan munculnya toko-toko baru: Toko Oey Boen Hong, Khoe Hong Tay milik orang Tionghoa. Kemudian, ada tiga toko milik orang Yahudi, yaitu Toko Ziekel, Salomon and Son, dan Toko Luphe. Ada pula tiga buah toko milik orang Belanda dan Prancis, yaitu Toko Thiem, Rouch, dan Baqiu (1986: 327).
}

dan Nugraha, 2008: 104; Hardjasaputra, 2002; 230). Secara umum, Bandung di tahun 1896 masih disebut bergdessa (desa pegunungan), orang-orang Eropa yang menghuni Kota Bandung masih berjumlah 600 jiwa (Kunto, 2014: 63). Meski belum begitu ramai, di penghujung abad ke-19 Bragaweg mulai diwarnai kehidupan ala Eropa ditandai dengan keberadaan Societeit yang terus berkembang dan munculnya toko-toko kebutuhan seharihari orang-orang Eropa.

\section{Modernisasi di Bragaweg}

Indikasi mulai terjadinya modernisasi di Bragaweg ditandai dengan munculnya toko-toko yang menjual barang-barang kebutuhan primer, kemudian bermunculan toko-toko yang menjual barang kebutuhan sekunder yang sifatnya lebih ke hiburan dan gaya hidup, khususnya pada awal abad ke-20. Semenjak Bandung ditetapkan sebagai gemeente (semacam kota otonom) pada 1906, semenjak saat itu pula kebijakan penataan kota cenderung ditentukan oleh segelintir elit Eropa; para preangerplanter dan pejabat pemerintah kolonial. Meskipun demikian, dalam beberapa hal terkait penataan jalan, Bupati Bandung R.A.A. Martanagara turut berperan aktif.

Indikasi lain dari modernisasi dari kawasan Braga adalah mulai dilakukannya perbaikan prasarana kota pada 1900. Bragaweg yang saat itu merupakan bagian dari Kerklaan (sekarang Jalan Perintis Kemerdekaan sampai ke ujung utara Jalan Braga) mengalami perbaikan jalan. Perbaikan jalan tersebut meliputi pengaspalan, termasuk perbaikan trotoar, pemasang lampu penerang jalan, dan penanaman pohon peneduh jalan. Perbaikan ini atas peran serta Vereeniging Tot Nut Van Bandoeng en Omstreken (semacam dewan kota saat itu). Pada tahun yang sama pula, tepatnya 1 Mei 1900 Bank Escompto berdiri di Bragaweg (Hardjasaputra, 2002: 323).

Sepanjang 1900 hingga 1910 berdiri enam buah toko di Bragaweg. Pada 
1902 berdiri toko De Vries yang dimiliki oleh Klaas de Vries. Toko ini menjual keperluan sehari-hari bagi para preangerplanter, mulai dari makanan dan minuman, peralatan dapur, kain, sepatu, alat tulis, dan obat-obatan. Haryoto Kunto menyebut Toko De Vries sebagai toko kelontong yang paling lengkap di masanya. Pamor Toko De Vries sebagai toko penyedian segala macam kebutuhan perlahan surut semenjak bermunculannya toko-toko lain yang menjual barang kebutuhan secara spesifik. Pada 1902 seorang apoteker bernama Verschoof membuka toko obat Rathkamp di ujung selatan Bragaweg. Di waktu yang bersamaan, bangunan toko tersebut digunakan pula untuk toko rokok Dunlop (Kunto, 1986: 327-329; Hutagalung dan Nugraha, 2008; 60).

Hingga 1902 bisa dikatakan toko yang muncul masih menjual barang keperluan yang sifatnya lebih primer, kebutuhan utama dan penting. Dari tahun 1904 hingga 1910 barulah mulai bermunculan toko yang mulai mengakomodasi gaya hidup khas Eropa. Pada 1904 dibuka toko alat musik J.H. Seeling en Zoon. Pada 1908 dibuka toko perhiasan dan arloji di Bragaweg dengan nama De Concurrent. Memasuki 1909, agaknya perekonomian di Bandung secara umum mengalami peningkatan ditandai dengan didirikannya De Javasche Bank di ujung utara Bragaweg. Bank ini menjadi bank kedua yang hadir di Bragaweg setelah Bank Escompto. Pada sekitar 1910an, beberapa perubahan terjadi di ujung utara Bragaweg. Sebuah gedung yang dikenal sebagai Goedang Oejah (gudang garam) mengalami kebakaran dan fungsinya diubah menjadi pasar bunga. Pada periode yang sama, dibuka restoran Maison Vogelpoel yang merupakan cabang dari perusahaan Th. Vogelpoel. Di sekitar Bragaweg bagian selatan, dibuka toko busana Onderling Belang yang menjual busana yang merujuk pada perkembangan mode di Amsterdam. Walaupun sudah mulai bermunculan toko-toko baru, tahun
1910 Bragaweg masih nampak asri dan rimbun dengan pekarangan toko yang cenderung luas serta ditanami pepohonan (Hutagalung dan Nugraha, 2008).

Koran De Preanger Bode pada 1911 menyebutkan Automobiel Club dalam sebuah kolom pemberitahuan. Isinya kurang lebih menyebutkan bahwa Soesman sebagai komisioner automobiel club, menyarankan agar pemilik mobil untuk mendaftarkan mobilnya dan meregistrasikan mobilnya ke kantor akuntan D.C.A. Lugt \& Co yang beralamat di Bragaweg no. 26 (De Preanger Bode, 23 Mei 1911). Hal ini mengungkapkan dua hal: 1) sudah ada kantor akuntan di Bragaweg, 2) besar kemungkinan mobil sudah mulai ada di Bandung. Hal ini agaknya sejalan dengan catatan Haryoto Kunto yang mengungkapkan bahwa F.J. Funch, seorang pengusaha Eropa, telah melakukan impor mobil di Hindia Belanda sejak 1886 (Kunto, 2014: 295). Sejalan dengan itu pula, sepanjang 1898 hingga 1906 mutu jalan di Bandung telah ditingkatkan, lapisan tanah telah diperkeras dengan lapisan batu. Mengacu pada video dari Netherlands Filmarchief (Koloniaal Instituut Amsterdam) yang diedit ulang oleh mahanagari.co.id terlihat bahwa antara tahun 1910 hingga 1930, kondisi Jalan Bragaweg sudah sangat baik; jalan rata dan mulus dapat dilalui kereta kuda.

Selain kondisi jalan yang sudah membaik, pada 1912 dan 1913 terjadi perubahan lain yang menarik, yaitu mulai munculnya toko pakaian/busana. Pada 1912 berdiri N.V. Kleedingmagazijn v.h. Firma Aug. Savelkoul yang merupakan perusahaan mode terkemuka. Toko ini merupakan toko pertama yang menyajikan layanan langsung ukur dan jahit berdasarkan badan pembeli. Pada 1913 dibuka toko busana berbasis mode Paris, Mode Magazijn Au Bon Marche. Bragaweg semakin terbentuk menjadi pusat perdagangan dan ekonomi elit Eropa.

Semenjak 1920 hingga 1930 begitu banyak toko yang dibuka di Bragaweg. Kondisi ini bisa dikaitkan 
dengan kebijakan elit kota, khususnya dewan Gemeente dan Burgermeester (walikota) Bandung ketika itu, B. Coops ${ }^{7}$. Kebijakan B. Coops terkait dengan Bragaweg adalah kebijakannya untuk menetapkan aturan, bahwa setiap bangunan yang berdiri di Bragaweg harus bergaya arsitektur Eropa. Dalam merealisasikan aturan ini, B. Coops dibantu oleh dua orang insinyur, Ir. J.P. Thysse dan Ir E.H. de Roo. Menurut Haryoto Kunto penerapan aturan ini karena konon B. Coops terinspirasi suasana pertokoan di Paris yang ia saksikan lewat sebuah film (Kunto, 2014). Realisasi dari aturan yang ditetapkan Coops ini agaknya tersirat dari mulai maraknya pendirian toko pada 1920.

Sebelum memasuki periode 1920 pada 1918 berdiri restoran yang kemudian menjadi restoran terkemuka dan menjadi favorit Gubernur Jenderal Hindia Belanda, yaitu Maison Bogerijen. Pada tahun yang sama, De Javasche Bank yang telah berdiri pada 1909 di ujung utara Bragaweg, mengalamai renovasi. Bangunan baru $D e$ Javasche bergaya indis (perpaduan gaya Eropa dan Nusantara) dirancang oleh Edward Cuypers. Besar kemungkinan renovasi De Javasche Bank bergaya Indis ini juga ada kaitannya dengan aturan yang ditetapkan B. Coops tentang pendirian bangunan bergaya Eropa di Bragaweg. Ambisi B. Coop bisa dikatakan semakin terealisasi pada 1920-an. Pada titik inilah modernisasi di Bragaweg bisa dikatakan mulai gencar dilakukan.

Pada periode itu berdiri beberapa toko di Bragaweg salah satunya Toko Kellers Kleiding Modemagazijn (toko busana) yang dibangun oleh arsitek G.J.

\footnotetext{
${ }^{7}$ Kebijakan B. Coops secara umum di Kota Bandung memang cukup membuat perubahan yang signifikan dan membangkitkan kesemarakan di Bandung. Coops menggagas diselenggarakannya festival tahunan Jaarbeurs. Festival tersebut, memungkinkan pengusaha Eropa untuk memamerkan segala produk yang dijualnya dalam sebuah acara tahunan yang semarak dengan hiburan.
}

Bel dengan menerapkan gaya art deco. Pada periode itu pula sudah terdapat toko lainnya di Bragaweg: Toko Bata, Salon de Coiffure Institut de Beaute, Toko G. en. J. de Leeuw, Toko Tatarah, Bongenaar Kunst Foto Studio, Ragusa Freres Tailleur, Sanghai Chemische Wasserij \& Ververij (Hutagalung dan Nugraha, 2008).

Selepas 1920 hingga 1930 perkembangan Bragaweg semakin pesat. Bermunculan toko otomotif, salah satunya Toko frits sluymers \& Co yang menjual produk Harley Davidson. Dibuka pula Toko Fuchs en Rens pada 1924 yang menjual beragam merk mobil seperti Pegeout dan Renault. Pada 1930-an pula sebuah pom bensin sudah berdiri di ujung utara Bragaweg, tidak jauh dari rel kereta api. Secara tersirat perkembangan ini menunjukkan bahwa pada periode 19201930 industri telah berkembang dengan cepat, sementara seturut itu pula kemajuan teknologi semakin terasa di kota kolonial seperti Bandung.

Majunya teknologi dan industri ini terefleksikan jelas di Bragaweg. Hal tersebut tentu saja menandai bahwa modernisasi di Bragaweg semakin terasa. Pada periode 1930-an berdiri Nederlandsch Indische Gas Maatschappij (perusahaan gas Hindia-Belanda) dan terdapat pula kantor N.V. Oliefabrieken Insulinde (Perusahaan Pabrik Minyak Nusantara) di Bragaweg. Puncak menguatnya ekonomi Hindia Belanda secara umum dan economic booming di Priangan, ditandai dengan berdirinya $D e$ Erste Nederlandsche Indische Spaarkas en Hypotheekbank (DENIS Bank) pada 1935. DENIS Bank berdiri pada sebuah bangunan megah bergaya art deco rancangan A.F. Aalbers (Kunto, 2014; De Preanger Bode, 26 Desember 1935).

Selain menjadi lokus penting ekonomi elit Eropa, di Bragaweg juga hadir hiburan mutakhir berupa tayangan gambar idoep di Concordia Bioscoop. Bioskop tersebut dirancang oleh Wolff Schoemaker dengan mengadopsi konsep Indis pada 1924. Bukan hanya hiburan dan 
gaya hidup, di Bragaweg pun tersedia sarana untuk keperluan perkembangan intelektual, yaitu Toko Buku Van Dorp yang berdiri pada 1922. Toko yang berdiri pada sebuah bangunan bergaya Indis rancangan Wolff Schoemaker ini, menjual segala buku langka, ensiklopedia, buku tanaman, hingga buku sejarah lengkap Hindia-Belanda (Kunto, 2014 ; Hutagalung dan Nugraha, 2008).

Bisa dikatakan pada 1936 di Bragaweg sudah lengkap dengan segala fasilitas; toko serba ada, toko obat, hiburan, restoran, salon, alat musik, perhiasan, furniture, busana, bank, showroom mobil, kantor perusahaan negara, toko buku, studio foto, pom bensin, kantor akuntan, kantor berita. Bragaweg di tahun 1930-an bukan hanya menjadi pusat ekonomi, tetapi juga menjadi salah satu pusat budaya elit Eropa.

Dari sisi infrastruktur, Bragaweg masuk dalam perencanaan Tjikapoendoengplan pada 1928, yaitu penetapan kawasan Jalan Raya Pos, Bragaweg, dan Banceuyweg sebagai kawasan pertokoan dan perkantoran. Rencana tersebut baru terealisasi pada 1938 dalam bentuk pembuatan jalan yang menghubungkan Bragaweg dengan Oude Hospitalweg. Rencana ini mengakibatkan pembongkaran Toko alat musik J.H. Seeling en $\mathrm{Zoon}^{8}$ serta sejumlah kampung ${ }^{9}$ bumiputra untuk dijadikan jalan (Hermawan, 2010). Mengacu pada video berjudul Bandung, Indonesia - A City Journey $^{10}, 1925$ yang diunggah oleh

\footnotetext{
$8 \quad$ Sekarang simpang Braga yang menghubungkan Braga ke Jalan Viaduct.

9 Dalam buku Braga: Revitalisation in an Urban Development, disebutkan bahwa sejumlah Kampung pribumi pada 1925, yaitu Kampung Banceuy, Kampung Haji Affandie, dan Kampung Cigantar. Ketika itu diindikasikan ada sejumlah pribumi yang bekerja sebagai penjaga kuda tinggal di kampung tersebut (Hutagalung dan Nugraha, 2008).

${ }^{10}$ Diakses 17 Oktober 2016.
}

Timescoop Indonesia di channel youtube, dapat diketahui bahwa pada 1925 Bragaweg telah diaspal dan disertai trotoar kurang lebih 1-2 meter. Mobil, kereta kuda, dan sepeda berlalu-lalang dengan mulus di Bragaweg, bahkan ada semacam pos polisi lalu lintas tepat di persimpangan ujung selatan Bragaweg dengan Jalan Raya Pos.

\section{Nuansa Modern dan Gaya Hidup Eropa}

Periode 1920 hingga 1930 merupakan masa keemasan kehidupan Elit Eropa di Bandung. Julukan Parijs van Java yang melekat di Kota Bandung bisa dilacak dari kemampuan elit Eropa ini untuk menjalin hubungan dengan pusat kebudayaan modern seperti Paris. Kemudian, orang-orang Eropa di Bandung tersebut mengadopsi hal-hal yang mereka temukan di Paris, Prancis.

Pada 1931, lima puluh orang seniman, tukang kayu, penjahit, pandai besi serta tukang cat perwakilan dari tokotoko terkemuka di Bragaweg ${ }^{11}$, di bawah pimpinan Ir. P.A.J. Mojeen, ikut serta dalam Wereldtentoonstelling (pameran dunia) di Paris. Keikutsertaan beberapa toko di Bragaweg pada even dunia ini membawa pengaruh yang tidak sedikit. Setelah ikut serta dalam Wereldtentoonstelling, nuansa Paris kental terasa dari penamaan toko yang mengadopsi bahasa Prancis, misalnya Modemagazijn Au Bon Marche, Maison Bogerijen, dan Maison Boin. Bukan hanya penamaan, tren busana pun bisa dengan cepat mengikuti perkembangan di Paris. Toko Mode Magazijn di Bragaweg misalnya dalam hitungan hari bisa memajang busana yang sedang tren di Paris di etalase toko mereka. Inilah salah satu unsur modern yang terasa di Braga, kemutakhiran dan kemampuan menjalin

\footnotetext{
11 Toko mebel Roth \& Son, De Concurrent, Firma Helerman, Firma Selling and Zoon, N.V. Keller's Mode Magazine, N.V. Onderling Belang, Firma Aug. Savelkoul, dan Meubel Maker Kero.
} 
koneksi untuk ikut serta dalam perkembangan dunia. Kecenderungan mengadopsi unsur Paris ini, ikut terasa dalam strategi promosi wisata yang dicanangkan elit Kota Bandung pada 1936 dengan menetapkan Parijs van Java sebagai julukan Bandung (Kunto, 2014: 70).

Nuansa modern ini sedikitnya bisa terlihat dari bagaimana unsur Barat, dalam hal ini Paris, ditiru dan diadopsi oleh beberapa toko di Bragaweg. Secara nyata hal ini bisa diamati dari iklan koran di masa itu, seperti yang termuat dalam $D e$ Preanger Bode 24 Desember 1921. Dengan tagline "mijn heele uitrusting kocht ik bij Au Bon Marche" (seluruh pakaian saya beli di Au Bon Marche) dengan gambar dua orang wanita; seorang memakai mantel bertopi lebar dan seorang lagi memakai gaun serta topi. Keduanya seolah sedang dalam perjalanan di tengah kapal laut. Melalui gambar tersebut, secara tersirat dapat dimaknai bahwa untuk menjadi trendi seperti di Paris, mereka tak perlu repot belanja di Paris, mereka dapat memperolehnya di tanah jajahan, di sebuah jalan di Bandung; Bragaweg.

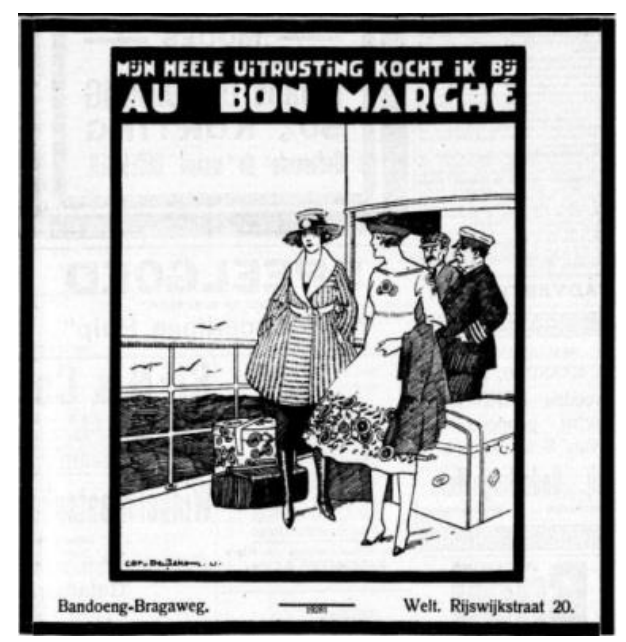

Gambar 2. Iklan Au Bon Marche Sumber: De Preanger Bode, 24

Desember 1921

Iklan Ini juga sedikitnya menggambarkan tingkat konsumsi golongan elit Eropa. Mereka bukan hanya mengejar kesuksesan dan pemenuhan kebutuhan primer di tanah jajahan, tetapi mereka turut membangun citra dan nilainilainya tersendiri; bahwa menjadi modis di tanah jajahan pun perlu. Golongan elit ini pada 1920-an setidaknya tak lagi disibukkan dengan cuaca tropis atau jalan yang becek, tetapi mereka mulai nyaman membentuk gaya hidupnya sebagaimana di tanah Eropa.

Sebagaimana dijelaskan oleh Rudolf Mrazek (2006) dalam bukunya Engineers of Happy Land, modern di Hindia Belanda dapat terlihat dari bagaimana perkembangan busana begitu terlihat mencolok, dan ditandai munculnya golongan pesolek. Deskripsi dari Mrazek ini setidaknya tergambar dari iklan koran, misalnya bagaimana pakaian dalam wanita/lingerie mulai lazim diiklankan (Het nieuws van den dag voor Nederlandsch-Indie, 3 November 1926).

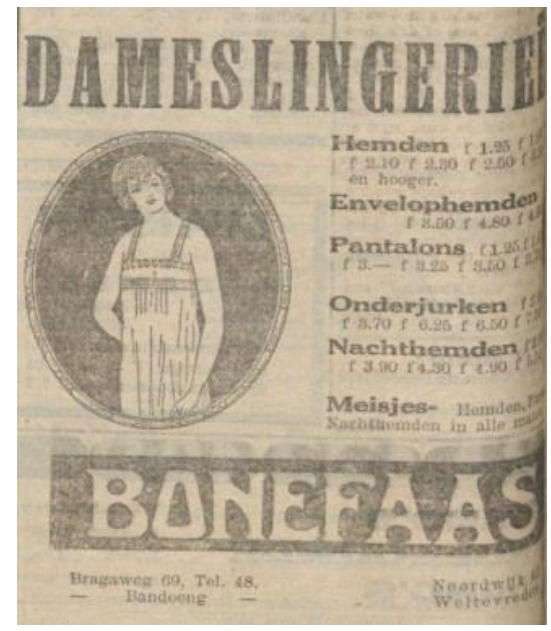

Gambar 3. Iklan Lingerie Bonefaas Sumber: Het nieuws van den dag voor Nederlandsch-Indie, 3 November 1926

Iklan dan promosi yang begitu kencang mengikuti tren ini berimplikasi pula dalam bentuk tontonan kemewahan etalase toko di Bragaweg. Selain melalui iklan, etalase toko menjadi media yang digunakan untuk mempromosikan produk. Misalnya bagaimana mobil-mobil mewah dipajang di showroom Fuch en Rent yang menjadi rebutan para preangerplanter 
untuk menunjukkan kekayaan mereka. Etalase toko di Bragaweg dibuat sedemikian rupa agar menarik dilihat. Salah satunya sebuah etalase toko jam, Michel Ehrlich Fuld di Bragaweg no. 67 ditata dengan etalase kaca yang besar, dekorasi yang rapi dan menawan, serta lampu yang berpendar di malam hari (De Jaarbeurs en Bandoeng 1921, hlm. 17). Display toko dirancang agar memikat pembeli, salah satunya diperlihatkan toko busana Onderling Belang di Bragaweg. Dengan ruang toko yang luas, segala busana dipampang dengan tata letak yang menarik. Beberapa busana dipamerkan dengan media boneka, beberapa lainnya seperti topi digantung menyemarakkan interior toko yang penuh dengan segala jenis barang (Jubileum Bandoeng, 1931).

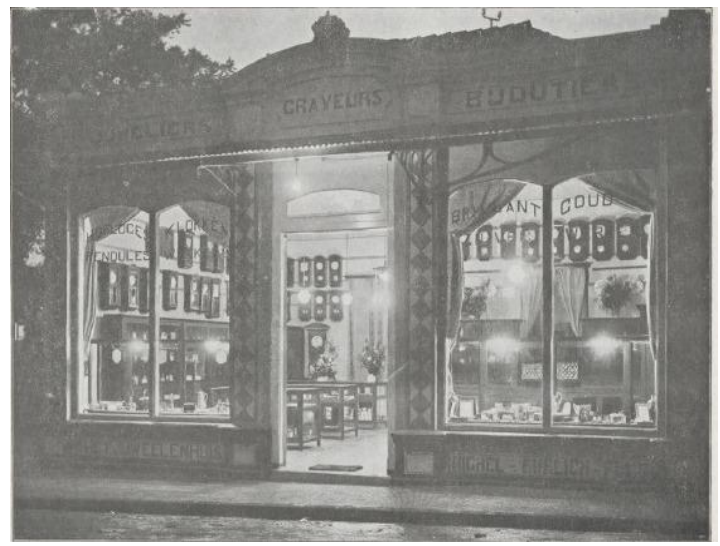

Gambar 4. Etalase toko jam, Michel Ehrlich Fuld di Bragaweg No. 67

Sumber: De Jaarbeurs en Bandoeng 1921

Bermunculannya iklan produk di koran dan semakin maraknya etalase toko yang memamerkan produk dengan menarik di Bragweg, merepresentasikan pesatnya perkembangan ritel di Bandung atau bahkan mungkin di Hindia Belanda pada periode 1920-an. Nuansa modern di Bragaweg dapat terasa dari semakin baiknya prasarana, dan terasanya perkembangan teknologi di kawasan tersebut. Hal ini dapat terukur dari mulai dipergunakannya telepon. Beberapa iklan produk dari sebuah toko di Bragaweg yang dimuat dalam koran sekitar tahun 1920-an, biasanya selalu menyertakan nomor telepon $^{12}$. Selain telepon, teknologi yang begitu nyata terasa adalah listrik. Sebagaimana nampak dalam gambar 4 , lampu sudah mulai menghiasi toko di Bragaweg. Lampu ini bukan hanya dipergunakan di toko tetapi juga dipasang sebagai penerang jalan yang sebelumnya masih menggunakan lampu gas. Setelah pendirian pembangkit tenaga listrik pada 1921 di Dago, kemudian dilakukan penambahan pembangkit listrik di Cisangkuy pada 1924, cahaya lampu listrik mulai dipasang hingga pelosok Kota Bandung pada 1926 (Kunto, 2014; 246, 299). Tentu saja Bragaweg sebagai salah satu pusat aktivitas golongan Eropa mendapatkan keistimewaan listrik ini.

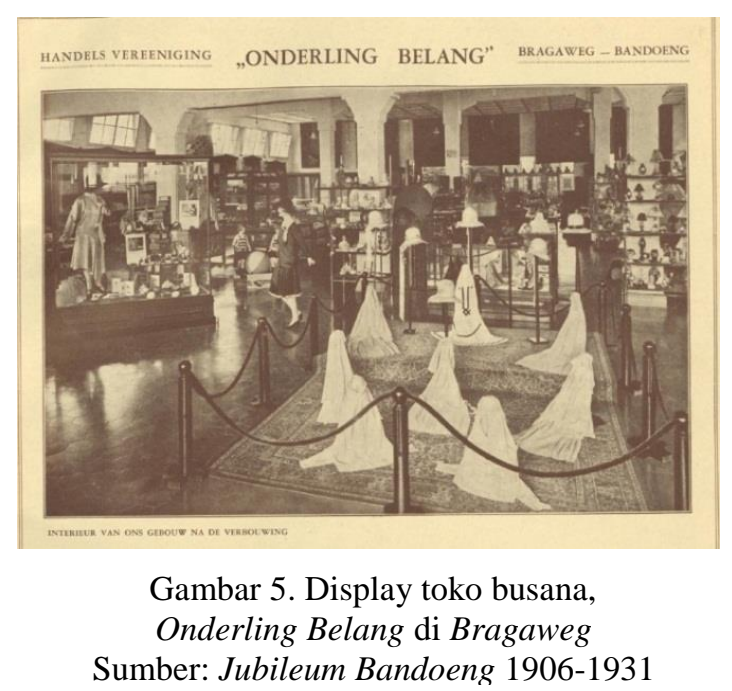

Demikian pun dengan sarana jalan, di mana sejak 1900, khususnya Bragaweg bagian utara ${ }^{13}$ menjadi salah satu ruas jalan yang pertama kali diaspal oleh pemerintah kota. Bukan hanya pengaspalan jalan, trotoar pun mengalami pembenahan (Hardjasaputra, 2002: 232). Baiknya

12 Iklan dalam Het nieuws van den dag voor Nederlandsch-Indie, 3 November 1926 iklan dalam Het nieuws van den dag voor Nederlandsch-Indie, 9 Mei 1935.

13 Ketika itu masih bagian dari ruas jalan Kerklaan 
kondisi jalan di Bragaweg, menunjang berbagai kendaraan seperti sepeda, delman, dan mobil melaju mulus di jalan tersebut. Pejalan kaki pun bisa nyaman berjalan karena trotoarnya luas (video Bandung, Indonesia- A City Journey, 1925 diunggah timescope Indonesia).

Baiknya sarana jalan di Bragaweg secara tidak langsung lebih membuka kemungkinan bagi banyak orang, khususnya orang-orang Eropa, untuk berbelanja di kawasan ini. Di sisi lain, baiknya sarana jalan lebih membuka ruang bagi elit Eropa untuk mempertontonkan kekayaannya melalui mobil-mobil yang mereka bawa dan parkirkan di Bragaweg. Hal ini sangat masuk akal mengingat pada tahun 1939 jumlah mobil di Bandung mencapai 4.945 unit. Dengan jumlah mobil sebanyak itu, tentu banyak di antaranya melewati atau singgah di Bragaweg (Mrazek, 2006: 25). Gambaran tentang ramainya situasi Bragaweg oleh kendaraan (mobil dan sepeda) serta orang-orang berlalu lalang terlihat jelas dalam foto-foto yang termuat dalam Album Bandoeng Tempo Doeloe (Katam dan Abadi, 2010).

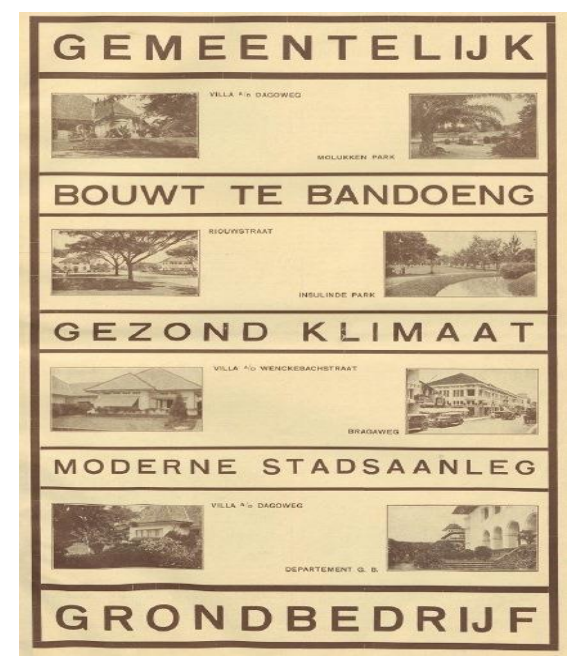

Gambar 6. Promosi wisata Kota Bandung Sumber: Jubileum Bandoeng 1906-1936

Citra modern yang tergambar dari suasana Bragaweg dibentuk pula oleh para elit kota. Hal ini terbukti melalui kesan yang ingin ditampilkan dalam promosi wisata. Misalnya, promosi wisata yang tertera dalam buku Jubileum Bandoeng 1906-1936. Dalam promosi wisata tersebut tertera kalimat: "Gemeentelijk Grondbedrijf, Bouwt te Bandoeng, Gezond Klimaat, Moderne Stadsaanleg" (Pembangunan Kota, Membangun Bandung, Iklim yang Sehat, Kontruksi Kota Modern). Pada promosi tersebut, kalimat Moderne Stadsaanleg (kontruksi modern) disandingkan dengan gambar suasana Bragaweg. Selain memperlihatkan kesan modern, kawasan Bragaweg memang sejak lama menjadi salah satu objek wisata unggulan yang ditawarkan dalam paket city tour Bandung yang diperkenalkan oleh Bandoeng Vooruit ${ }^{14}$ (Budiman, 2010: 93).

Elit Eropa hidup dengan nuansa dan nilai-nilai ke-Eropa-annya di ruang yang mereka ciptakan sendiri. Bragaweg adalah contoh konkret itu, di mana batasan terbentuk dari bagaimana Elit Eropa mempraktikkan atau mempertontonkan gaya hidupnya. Gaya hidup yang dimaksud tentu saja berbeda jauh, bahkan boleh jadi tak lazim bagi bumiputra. Salah satu contoh yang paling unik sekaligus mencolok adalah Festival St. Nicolaas (perayaan Natal dengan mendatangkan Santa Claus) yang telah dilangsungkan di Jawa sejak 1870. John Helsloot (1998) dalam penelitiannya, St Nicholas as a Public Festival in Java (1870-1920), menjelaskan St. Nicholas Festival dilakukan di beberapa kota besar di Jawa seperti Batavia, Surabaya dan Bandung. Uniknya, festival ini harus menyesuaikan dengan iklim dan kondisi masyarakat Hindia Belanda. St Nicholas lazimnya dirayakan secara intim di rumah dengan pohon natal dan kado-kado. Di Hindia Belanda, festival ini justru dilakukan secara terbuka (di jalan atau taman kota) dan bisa disaksikan pula oleh orang-orang bumiputra. Namun demikian, di kota-kota

14 organisasi kemasyarakatan yang diisi oleh elit Eropa dan elit bumiputra. Salah satu tugasnya membenahi kota dan mempromosikan wisata di Kota Bandung. 
besar yang infrastrukturnya maju, Festival St. Nicholas mulai dilaksanakan di restoran atau café dengan interior lengkap disertai musik, segala jenis makanan: kue, ice cream, dan pastry. Bukan hanya interior, sang St. Nicholas datang dengan penampilan khusus seperti dijelaskan Helsloot (1998: 621) "the saint whose day it was would make a personal appearance, sometimes mounted on his traditional grey horse and accompanied by his servant, Black Peter, who would distribute presents to the children".

Deskripsi yang dikemukakan Helsloot ini agaknya terjadi pula di Bragaweg sebagai salah satu pusat kehidupan Eropa. Dalam Algemeen Indisch Daagblad de Preangerbode, 1 Desember 1923 terdapat sebuah pemberitahuan bahwa pada 5 Desember pukul 05.45 sore akan tiba St. Nicholas di Maison Bogerijen untuk membagikan kado kepada setiap anak. Maison Bogerijen adalah salah satu restoran terkemuka di Bragaweg. Datangnya St. Nicholas ke Maison Bogerijn di Bragaweg, agaknya dapat dipahami dalam penjelasan yang didedahkan Helsloot (1998: 621), "the festivities were usually restricted to a limited area surrounding the most popular confectioners' shop, which had their bands playing. In this small social space people, many of them in small groups, would wave to each other from one restaurant to another". Penyelenggaraan St. Nicholas Festival ini, menurut Helsloot, menghadirkan simbolic etnicity of Dutch culture atau sense of Dutchness yang kadang tercermin dari lagu nasional Belanda yang sering kali turut dimainkan dalam festival tersebut. Hal ini mempertegas batasan etnis antara siapa Belanda dan siapa bumiputra atau Timur Asing itu (Helsloot, 1998: 625).

Bragaweg adalah ruang di mana elit Eropa menunjukkan dominasinya yang tercermin lewat budaya yang dipraktikkan para elit ini. Bukan hanya melalui St. Nicholas Festival, budaya para elit ini juga terlihat dari bagaimana mereka menghadirkan hiburan, misalnya melalui tonil (sandiwara) yang sejak 1882 telah dipertunjukkan di kawasan Bragaweg, khususnya di Societeit Concordia. Para pemain tonil ini terkadang menampilkan lakon-lakon Shakespeare dengan dekorasi dan pakaian yang serba mewah atau menampilkan opera Madame Butterfly yang menampilkan gadis-gadis cantik dengan gaun dan kipas (Kunto 1986: 267; Kunto 2014: 183).

Bisa dikatakan Societeit Concordia merupakan pusat hiburan orang-orang Eropa di kawasan Bragaweg. Menurut L.H.C Horsting, Societeit Concordia Bandung merupakan societeit yang terdepan dengan segala aktivitas dan fasilitas di dalamnya. Kegiatan di Societeit Concordia selalu padat, khususnya di akhir pekan sebagaimana dijelaskan dengan sangat rinci oleh Hutagalung dan Nugraha (2008). Pada sabtu pagi, anggota societeit sudah hadir untuk bersosialisasi dan mendengarkan orkes musik. Mereka menghabiskan waktu hingga sore hari, kemudian menjelang malam menenggak minuman keras. Pada malam hari, para elit Eropa ini mulai berdandan rapi dan modis untuk mengikuti pesta dansa. Keesokan harinya, anggota societeit, khususnya para remaja biasa mempergunakan ruangan untuk bermain sepatu roda, terkadang diselingi pertunjukan musik yang ditampilkan secara spontan. Societeit Concordia Bandung memiliki agenda tetap di hari Kamis dan Sabtu. Biasanya diisi oleh rangkaian acara pesta dansa, konser musik, kemudian acara ditutup dengan pesta dansa kembali. Selain acara mingguan, Societeit Concordia memiliki agenda tiga bulanan yaitu acara Bragabal yang meliputi pentas musik serta pesta dansa dengan dandanan yang amat meriah. Pada momen pergantian tahun, agenda acara di Societeit dikemas secara lebih menarik. Orkes musik dan pesta dansa dilengkapi dengan jamuan makan mewah dihidangkan dari restoran kenamaan di Bragaweg. 
Tingginya aktivitas golongan Eropa di Societeit Concordia mendorong pengelola Societeit menyediakan gedung yang lebih besar. Pada 1921 dibangunlah gedung tambahan yang dinamakan Schouwburg. Di Gedung inilah aktivitas Societeit Concordia semakin semarak dan variatif; mulai dari teater, konser musik, dansa, tari balet, pameran lukisan, dan perayaan tertentu. Teater dengan lakon sastra klasik pun ditampilkan dengan serius di Societeit. Pesatnya perkembangan aktivitas kebudayaan di Societeit terbukti dari diundangnya balerina kawakan asal Rusia, Anna Pavlova, untuk tampil di Societeit pada 1929. Bisa dikatakan Societeit Concordia, atau Bragaweg secara umum, merupakan salah satu pusat kebudayaan orang-orang Eropa. Aktivitas di Societeit pun didukung oleh komunitas seni seperti Bandoengsche Kunstkring (Himpunan Kesenian Bandung) yang sudah berdiri sejak 1904 (Hutagalung dan Nugraha, 2008: 53-57; Kunto, 2014: 155).

Dari aktivitas hiburan, seni, dan interaksi elit Eropa yang berlangsung di Societeit, besar kemungkinan turut mendorong terbentuknya trend dan fashion busana di tengah mereka. Hadirnya tokotoko ritel yang menawarkan barang mewah atau busana mode Paris di Bragaweg, boleh jadi secara tidak langsung didorong oleh tuntutan pergaulan dan gaya hidup yang tumbuh di tengah interaksi golongan elit Eropa di Societeit. Para elit berlomba menampilkan citra mewah layaknya bangsawan Eropa di abad ke-17. Pada titik ini, penulis berargumen bahwa dari berkembangnya pergaulan elit Eropa di Societeit Concordia inilah mampu menjadi "bola salju" untuk terciptanya kehidupan bergaya Eropa sepajang Bragaweg.

Semaraknya aktivitas di Societeit Concordia merupakan salah satu indikasi terciptanya kehidupan bergaya Eropa. Gaya hidup Eropa ini seringkali identik dengan modern; suatu upaya untuk ikut dalam perkembangan zaman yang dinamis. Indikasi lain dari terbentuknya kehidupan gaya Eropa yang modern, antara lain muncul dan hidupnya komunitas hobi di Bragaweg. Berdasarkan penelusuran penulis, di sekitar tahun 1911 hingga 1930an sudah ada komunitas seperti Automobiel $C l u b^{15}$ (komunitas pengendara mobil), De Preanger Amateur Fotografen Club ${ }^{16}$ (komunitas fotografer amatir), bahkan ada pula sekelompok pengendara motor yang biasa berkumpul di Bragaweg ${ }^{17}$. Gaya hidup Eropa ini terlihat pula dari kebiasaan menyaksikan film/gambar idoep di bioskop Majestic yang berlokasi di Bragaweg. Film yang diputar tentu saja berkiblat ke Barat, khususnya film-film Holywood, misalnya The Black Box, The Broken Coin, dan Liberty. Seperti dikemukakan Haryoto Kunto, hadirnya film turut berpengaruh pada mode busana, misalnya populernya film Zigomar mengakibatkan banyak pria pada 1920 -an memakai topi filt ala bandit. Masifnya peniruan mode topi ini mengakibatkan pemerintah kolonial sempat melarang pemutaran film Zigomar tersebut (Kunto, 1986: 436). Hal ini sekali lagi membuktikan bagaimana modern itu dinikmati secara nyata oleh elit Eropa.

Kebiasaan makan-makan dan mendengarkan musik di restoran mewah menjadi salah satu indikasi gaya hidup Eropa yang modern di Bragaweg. Misalnya kebiasaan makan dengan menumenu khas Belanda, minum bir sambil diiringi orkes musik di restoran Maison Bogerijn. Dalam De Preangerbode 6 September 1918 tercantum sebuah iklan Maison Bogerijn yang menyebutkan akan menggelar orkes musik pada 8 September yang ditampilkan pada pukul 11 siang hingga pukul 1 siang, untuk malam hari orkes musik dimulai sejak pukul 7 malam hingga 08.30 malam. Maison Bogerijn yang dimiliki oleh L.V. Bogerijen, mantan penguasaha firma Stam en Wijns ini, turut menawarkan satu gentong besar bir dengan harga per gelasnya f. 0.70 .

\footnotetext{
${ }^{15}$ De Preanger Bode, 23 Mei 1911.

${ }^{16}$ Bataviaasch Nieuwsblad, 12 Februari 1930

${ }^{17}$ Kunto, 1996: 57.
} 
Selain gaya hidup Eropa yang modern, keberadaan kawasan Bragaweg turut mempertegas kelas sosial, di mana aktivitas di jalan yang tak lebih dari $1 \mathrm{~km}$ ini, cenderung diisi oleh aktivitas golongan orang-orang kaya seperti yang termuat dalam Bataviaasch Nieuwsblad 15 September 1937 yang menjelaskan macetnya lalu lintas di Bragaweg karena pertemuan kelas menengah Bandung. Dalam sebuah judul besar tertulis " $D e$ Bandoengsche Middenstand Vergadert; Bedankt voor Lidmaatschap Federatie" yang artinya; Pertemuan Kelas Menengah Bandung; Terima Kasih untuk Semua Anggota Federasi”. Di sisi lain, batasan rasial pun dipertegas di Bragaweg sebagaimana tersirat dalam karya-karya Haryoto Kunto (1986, 2014) serta Hutagalung (2008). Golongan Bumiputra nyaris tak memiliki ruang di Bragaweg, bahkan golongan Indo-Eropa pun (misalnya Indo-Europeesche Verbond $C l u b^{18}$ ) hanya mendapatkan ruang yang minor di Bragaweg. Para keturunan IndoEropa hanya memakai sebuah gedung untuk hiburan yang kesemarakan acaranya kalah jauh dengan Societeit Concordia. Lebih memprihatinkan lagi, sebuah jalan kecil yang menghubungkan Bragaweg dengan Tamblongweg justru sering diidentikkan sebagai kawasan bordil yang diisi oleh wanita-wanita keturunan IndoEropa. Bagaimana pula golongan bumiputra di Bragaweg? Seperti jelas terlihat dalam video Bandung, Indonesia A City Journey 1925, kaum bumiputra yang berkulit gelap mengenakan ikat kepala, berdiri di belakang tuan-tuan Belanda, menunggu perintah dari majikannya. Para majikan ini duduk-duduk di pelataran Societeit Concordia, mengamati hiruk pikuk lalu lintas di Bragaweg.

Menjelang akhir kekuasaan Hindia Belanda, ruang di Bragaweg mulai terbuka bagi kaum bumiputra. Pada 1943, atas

\footnotetext{
${ }^{18}$ Eksistensi Indo-Europeesche Verbond Club (IEV Club) tercantum dalam berita Bataviaasch Nieuwsblad, 19 September 1929.
}

bantuan Soewardi Suryadiningrat, Ajoem Kasoem menjadi pelopor kaum bumiputra yang mampu membuka toko di Bragaweg. Hingga kini Kasoem terkenal sebagai produsen kacamata/optik terkemuka ${ }^{19}$.

\section{Redupnya Kegemerlapan Bragaweg}

Koran De Preangerbode tertanggal

29 Januari 1947 masih memperlihatkan beberapa iklan toko yang berada di Bragaweg, seperti toko perhiasan De Contcurrent dan Rest. California Casino di Bragaweg. Namun demikian, di koran tersebut mulai muncul iklan Tionghoa Restaurant dan Cine Radio Horloge Reparatie. Toko Tionghoa agaknya mulai mendapat ruang di Bragaweg. Sementara itu, koran De Preangerbode tertanggal 4 Mei 1947 masih mencantumkan beberapa daftar toko busana bernuansa Belanda di Bragaweg seperti Onderling Belang, Au Bon Marche, dan Populair. Artinya, tokotoko milik Belanda/Eropa masih eksis di Bragaweg pada 1947, tetapi pengusaha Tionghoa mulai mengambil alih tokotoko $^{20}$ yang ditinggalkan pemiliknya. Hal tersebut terlihat jelas dalam salah satu foto Album Kenangan Kodam Siliwangi (1977), di mana papan toko De Vries (sekarang Bank NISP) sudah berganti dengan papan nama toko bertuliskan huruf Tionghoa.

Pecahnya perang mempertahankan kemerdekaan yang dilakukan oleh bumiputra, mengakibatkan situasi di Bragaweg tak sekondusif ketika pemerintah Hindia Belanda masih berkuasa penuh. Pada masa berlangsungnya Agresi Militer Belanda I, atau setahun setelah peristiwa Bandung Lautan Api, pada 1947 pasukan militer KNIL dengan sejumlah kendaraan perang sempat menduduki Bragaweg (Katam dan Abadi, 2010: 38). Militer Belanda menguasai Kota Bandung sebelah Utara (kawasan Eropa), Bragaweg termasuk pula

\footnotetext{
${ }^{19}$ http://www.santijehannanda.com/2014/07/23/

kisah-a-kasoem/, diakses 25 Januari 2017

${ }^{20}$ (http://www.santijehannanda.com/2014/07/23

/kisah-a-kasoem/, diakses 25 Januari 2017).
} 
di dalamnya (Smail, 2011). Pada periode 1947 hingga 1949, kawasan Braga lebih banyak dipergunakan oleh kalangan militer Belanda. Mengacu pada salah satu koleksi foto nomor 101855 Het militaire leven, Nederlands Nationaal Militair Museum, Soesterberg, dapat diketahui semasa perang, gedung Societeit Concordia masih sempat dipergunakan untuk sebuah pertunjukan tari dengan judul "The Last Meal". Pertunjukan tersebut disaksikan langsung oleh salah satu pejabat militer Belanda, Mayor Jenderal van Goor dari Mahkamah Militer Agung ${ }^{21}$.

Memasuki 1949, kawasan Bragaweg meredup kesemarakannya. Meskipun toko-toko Eropa dan gedung hiburan seperti Societeit Concordia masih eksis, namun lebih dipergunakan oleh kalangan militer Belanda. Dalam ruang lingkup yang lebih luas, Kota Bandung menjadi medan pertempuran antara tentara republik dengan militer sekutu/Belanda. Salah satu peristiwa heroik menjelang pecahnya Peristiwa Bandung Lautan Api, terjadi di Bragaweg, tepatnya di Gedung DENIS Bank. Terjadi perobekan bendera Belanda yang dilakukan oleh dua orang pemuda, Karmas dan Moeljono. Hingga saat ini sebuah stilasi peringatan Bandung Lautan Api dibangun di dekat bangunan DENIS Bank (sekarang Bank BJB) untuk mengenang peristiwa heroik tersebut (Katam dan Abadi, 2010: 332; Smail, 2011).

\section{PENUTUP}

Bragaweg pada awalnya dikenal sebagai Jalan Pedati. Jalan tersebut digunakan untuk mengangkut komoditas kopi dari

${ }^{21}$ Dienst voor Legercontacten. "GeneraalMajoor van Goor van het Hoog Militair Gerechtshof en de Wali Negara van Pasoendan in de Sociëteit Concordia te Bandoeng". Koleksi 101855 Het militaire leven, Nederlands Nationaal Militair Museum, Soesterberg (http://www.geheugenvannederland.nl/nl/geheu gen/, diakses 22 Januari 2017)
Jalan Raya Pos ke Gudang Kopi. Jalan Pedati mulai berubah setelah Bandung ditetapkan sebagai Ibukota Keresidenan Priangan pada 1864. Salah satu faktor penting yang membangkitkan Jalan Pedati menjadi jalan yang ramai adalah berdirinya Societeit Concordia pada 1879. Dibangunnya transportasi kereta di Bandung pada 1884, mendukung kedatangan orang-orang Eropal prangerplanters untuk turut mencari hiburan di Societeit Concordia. Semaraknya aktivitas Societeit Concordia pada abad ke-20 berimbas pada terciptanya kehidupan Eropa di sekitar Bragaweg.

Seiring dengan semakin ramainya orang-orang Eropa datang ke Societeit Concordia, modernisasi di kawasan Bragaweg pun mulai terjadi. Modernisasi awal di Bragaweg ditandai dengan berdirinya toko kebutuhan Eropa untuk pertama kalinya, yaitu N.V. Hellermann pada 1894. Indikasi lainnya yang menunjukkan bahwa terjadi modernisasi di Bragaweg, meliputi: 1) munculnya tokotoko dan restoran yang orientasinya untuk mengakomodasi gaya hidup orang-orang Eropa yang mewah; 2) beragam toko yang berdiri di Bragaweg mampu mengikuti perkembangan trend global, khususnya Paris; 3) memasuki tahun 1920-an mulai berdiri bank dan mulai dibukanya tokotoko yang menjual barang yang sangat mewah, yaitu motor dan mobil; 4) mulai terciptanya promosi melalui iklan di koran serta etalase toko yang dibuat dengan sangat menarik; 5) penataan kawasan Braga dengan fasilitas yang lengkap (jalan aspal, trotoar yang lebar, lampu jalan, listrik, dan telepon); 6) kebijakan Walikota Bandung saat itu, B. Coops, yang mengharuskan bangunan di kawasan Bragaweg bercirikan arsitektur Eropa; dan 7) citra modern kawasan Bragaweg berusaha dilekatkan oleh Gemeente Bandoeng melalui promosi wisata.

Modernisasi yang terjadi di Bragaweg terjadi seiring dengan tumbuh dan berkembangnya gaya hidup Eropa. Gaya hidup Eropa ini ditunjukkan dengan 
membiasakan tradisi yang dilakukan di Barat, misalnya menyelenggarakan St. Nicholas Festival. Bragaweg menjadi ruang di mana tradisi Eropa biasa dipraktikkan, antara lain: menonton hiburan berupa tonil, mendengarkan orkes musik, berdansa, makan dan bersosialisasi, serta menonton film di bioskop. Bukti bahwa gaya hidup Eropa mewarnai suasana di Bragaweg dapat dilihat dari munculnya komunitas-komunitas hobi yang melakukan aktivitasnya di Bragaweg. Komunitas yang dimaksud, antara lain: Automobiel Club (komunitas pengendara mobil), De Preanger Amateur Fotografen Club (komunitas fotografer amatir), komunitas pengendara motor, dan Bandoengsche Kunstkring (Himpunan Kesenian Bandung). Di sisi lain, gemerlapnya kehidupan di Bragaweg cenderung mempertegas kelas sosial, bahkan di antara golongan Eropa sendiri.

Ketika perang mempertahankan kemerdekaan bergolak di Bandung pada 1947 hingga 1949, gemerlap kehidupan modern ala Eropa di Bragaweg mulai pudar. Ketidakstabilan keamanan terjadi di masa itu, pengusaha Tionghoa justru mulai membuka toko di Braga. Di saat yang sama Bragaweg mulai diduduki militer Belanda dan diselimuti suasana perang.

\section{DAFTAR SUMBER}

\section{Jurnal}

Helsloot, John. "St. Nicholas as a Public Festival in Java, 1870-1920: Articulating Dutch Popular Culture as Ethnic Culture" dalam Bijdragen tot de Taal, Land, en Volkenkunde. Vol. 154, No. 4. 1998.

\section{Buku}

Basundoro, Purnawan. 2012.

Merebut Ruang Kota: Aksi Rakyat Miskin Kota Surabaya 1900-1960-an. Tangerang: Marjin Kiri.

Budiman, Hary Ganjar. 2010. Taman Kota di Bandung (1885-1945). Skripsi. Jatinangor: Fakultas Sastra Universitas Padjadjaran.

Daryanto, Totok. 1989.
Sosiologi Modernisasi. Yogyakarta: Tiara Wacana Yogya.

Colombijn, freek., Martine Barwegen, Purnawan Basundoro, dan Johny Alfian Khusyairi. 2005.

Kota Lama Kota Baru; Sejarah Kotakota di Indonesia. Yogyakarta: Ombak.

Hardjasaputra, Sobana. 2002.

Perubahan Sosial di Kota Bandung 1810-1906. Disertasi. Depok: Universitas Indonesia.

Hermawan, Iwan. 2010.

Braga sebagai Pusat Perdagangan Bandung Tempo Dulu. Jatinangor: Alqaprint.

Hutagalung, Ridwan, dan Taufanny Nugraha. 2008.

Braga; Jantung Parijs van Java. Bandung: Ka Bandung.

Katam, Sudarsono dan Lulus Abadi. 2010. Album Bandoeng Tempo Doeloe. Bandung: Nav Press.

Kodam VI Siliwangi. 1977. Album Kenangan Kodam VI/Siliwangi 1946-1977. Bandung: Kodam VI Siliwangi.

Kunto, Haryoto. 1986. Semerbak Bunga di Bandung Raya. Bandung: Granesia. 2014.

Wajah Bandoeng Tempo Doeloe. Bandung: Granesia.

Mrazek, Rudolf. 2006. Engineers of Happy Land. Jakarta: Obor.

\section{Koran}

Bataviaasch Nieuwsblad, 19 September 1929. Bataviaasch Nieuwsblad, 12 Februari 1930. Bataviaasch Nieuwsblad, 15 September 1937. De Preanger Bode, 22 September 1902 De Preanger Bode, 23 Mei 1911.

De Preanger Bode 6 September 1918.

De Preanger Bode 24 Desember 1921.

De Preangerbode, 1 Desember 1923

De Preanger Bode, 8 Maret 1930

De Preanger Bode, 26 Desember 1935.

De Preanger Bode 25 November 1952.

De Preanger Bode 2 Juli 1956.

Het nieuws van den dag voor NederlandschIndie, 3 November 1926. 
Het nieuws van den dag voor NederlandschIndie, 9 Mei 1935.

De Jaarbeurs en Bandoeng 1921.

Jubileum Bandoeng 1906-1931, 1931.

\section{Video}

"Bandung, Indonesia A City Journey" diunggah di youtube.com oleh Timescoop Indonesia, diakses 17 Oktober 2016.

"Kehidupan Kota Bandoeng 1910-1930" diunggah di youtube.com oleh Mahanagari, diakses 17 Oktober 2016.

\section{Internet}

http://www.geheugenvannederland.nl/nl/geheu gen/, diakses 22 Januari 2017.

http://www.isyharyanto.wordpress.com, diakses 17 Januari 2016.

http://www.santijehannanda.com/2014/07/23/ki sah-a-kasoem/, diakses 25 Januari 2017. 